\title{
Dielectric Dispersion Modulated Sensing of Yeast Suspension Electroporation
}

\author{
Guilherme B. Pintarelli ${ }^{1, *(\mathbb{C}}$, Jessica R. da Silva ${ }^{1}$, Wuqiang Yang ${ }^{2}{ }^{(0)}$ and Daniela O. H. Suzuki ${ }^{1} \mathbb{C}$ \\ 1 Department of Electrical and Electronics Engineering, Institute of Biomedical Engineering, Federal University \\ of Santa Catarina (UFSC), Florianopolis 88040-370, Brazil; jessica.rodrigues@posgrad.ufsc.br (J.R.d.S.); \\ daniela@ppgeel.ufsc.br (D.O.H.S.) \\ 2 Department of Electrical and Electronic Engineering, The University of Manchester, Manchester M13 9PL, UK; \\ wuqiang.yang@manchester.ac.uk \\ * Correspondence: guilherme.pintarelli@ufsc.br
}

Citation: Pintarelli, G.B.; da Silva, J.R.; Yang, W.; Suzuki, D.O.H Dielectric Dispersion Modulated Sensing of Yeast Suspension Electroporation. Sensors 2022, 22, 1811. https://doi.org/10.3390/ s22051811

Academic Editors: Faisal Mohd-Yasin and Ahmet Can Sabuncu

Received: 28 December 2021

Accepted: 23 February 2022

Published: 25 February 2022

Publisher's Note: MDPI stays neutral with regard to jurisdictional claims in published maps and institutional affiliations.

Copyright: (C) 2022 by the authors. Licensee MDPI, Basel, Switzerland. This article is an open access article distributed under the terms and conditions of the Creative Commons Attribution (CC BY) license (https:// creativecommons.org/licenses/by/ $4.0 /)$

\begin{abstract}
A specific pulsed electric field protocol can be used to induce electroporation. This is used in the food industry for yeast pasteurization, in laboratories for generic transfer and the medical field for cancer treatment. The sensing of electroporation can be done with simple 'instantaneous' voltagecurrent analysis. However, there are some intrinsic low-frequency phenomena superposing the electroporation current, such as electrode polarization. The biological media are non-homogeneous, giving them specific characterization in the broad frequency spectrum. For example, the cell barrier, i.e., cell membrane, causes so called $\beta$-dispersion in the frequency range of tens to thousands of $\mathrm{kHz}$. Electroporation is a dynamic phenomenon characterized by altering the cell membrane permeability. In this work, we show that the impedance measurement at certain frequencies could be used to detect the occurrence of electroporation, i.e., dielectric dispersion modulated sensing. This approach may be used for the design and implementation of electroporation systems. Yeast suspension electroporation is simulated to show changes in the frequency spectrum. Moreover, the alteration depends on characteristics of the system. Three types of external buffers and their characteristics are evaluated.
\end{abstract}

Keywords: pulsed electric field; bio-impedance; biological system modeling; bio-technology; bio-membranes

\section{Introduction}

Pulsed Electric Field (PEF) is a non-thermal electricity-based process to control cells. PEF is used in bio-technology [1], veterinary [2] and medical research [3], and food industry $[4,5]$. These applications require specific levels of electroporation control. Techniques and sensing electroporation improve safety and optimization applications of PEFs. Recent progress on electroporation methods propose studies of PEF using nanoparticles [6], gels [7,8], microdevices [9], and electrospun PCL [10].

The PEF approach makes use of a combination of pulse amplitudes, pulse durations and pulse repetitions. Usually, high amplitude, short duration, and rectangular PEF (hundreds of $\mathrm{kV} / \mathrm{m}$ and tens to hundreds of $\mu \mathrm{s}$ ) is used for the permeabilization of the cell membrane, also known as electroporation or electro-permeabilization [11,12]. Electroporation can arise as reversible or irreversible, mainly depending on the PEF amplitude. If PEF is configured as low amplitude and long duration (tens of $\mathrm{kV} / \mathrm{m}$ and tens $\mathrm{ms}$ ), it is possible to primarily cause electrolysis, which may induce chemical ablation $[13,14]$.

The electroporation theory is based on formation of nano-pores in the cell membrane due to excessive accumulation of transmembrane ionic charges. Pore hypothesis evidence is given by measurements showing the increase in ionic permeability due to PEF. Pore creation and expansion is described to change the membrane electrical properties (e.g., electrical conductivity) [15]. The pore number can be described by the Smoluchowski equation [16]. The membrane changes affect the macroscopic scale electrical properties, 
which can be modeled using a macroscopic current. This concept is mostly used to describe PEF tissue response, which enables the pre-treatment of PEF-based cancer therapies $[17,18]$. PEF is usually delivered in the signature of $100 \mu$ sectangular pulses burst, which is described by diverse sub- $4.4 \mathrm{kHz}$ frequency components. Current models use instantaneous current-voltage measurements to describe the PEF electrical current $[18,19]$, which is a sum of conduction current, dispersive effects, electrode-biological-media polarization, and electroporation. From the engineering point of view, differentiating the electroporation current from other PEF-current is complex. We call the electroporation current the superimposed non-physiological displacement current in the cell membrane due to pore opening. It is known that the biological systems are electrolytes and charges are subject to changes in polarization, i.e., orientation and displacement of charges. The polarization delay is given in the time domain, and it is called relaxation, which can be transposed to the frequency domain, so-called dispersion. Biological systems are characterized by the three most expressive relaxation factors: ions diffusion outside the cells, cell's membrane interface charging, and molecule orientation, which contribute to Schwan's dispersions, $\alpha$, $\beta$, and $\gamma$, respectively [20]. The $\alpha$-dispersion and electrode-biological-media-dispersion are located at sub- $10 \mathrm{kHz}$, which is where the PEF burst energy spectrum is. Those phenomenon dynamics have not been completely understood, interfering in the direct current measurement.

Besides the complexity of characterizing biological samples using sub- $10 \mathrm{kHz}$ measurements, the electroporation itself is not entirely understood. Thus, PEF systems usually do not have electroporation feedback because there is no adequate PEF probing method. We have recently shown that it is possible to eliminate yeast using irreversible electroporation and the macroscopic current changes due to cell breakage [4]. Yeasts are a problem in the industry, as their contamination can cause financial loss. If contaminated yeast is injected into a human body, it can cause health problems. However, there are no efficient methods to sense electroporation for probing the actual electroporation current, which can be ultimately used to directly probe the membrane conductivity or electroporation pore density. In this work, we evaluated the effects of electroporation on the dielectric spectrum of cell suspensions. This evaluation can provide insights into the development of electroporation/PEF high frequency $(>10 \mathrm{kHz})$ sensors. New sensors can be designed to operate in a frequency range adequate for detecting membrane changes while avoiding sub- $10 \mathrm{kHz}$ PEF direct current polarization disturbances. This technique provides more accurate readings of electroporation mechanisms to control and optimize industrial processes.

To demonstrate the feasibility of supervising electroporation, we propose a numerical study on the sensing of the suspension dielectric dispersion. Yeast cell suspension is known to have well-defined $\beta$-dielectric dispersion in the frequency range of $0.1-1 \mathrm{MHz}$ due to the cell membrane. The electroporation model is used to calculate changes in the membrane conductivity $\left(\sigma_{m}\right)$ during electroporation. System invariance is assumed on a small scale, and the suspension dielectric spectrum is calculated. A computer model is used to demonstrate that the system dielectric dispersion changes due to the cells' membrane and their interaction with the extracellular media and electroporation. This technique may be applied at a microsensor embedded at an industrial electroporation line or an electroporation lab on a chip device.

\section{Materials and Methods}

Analytical approaches to solving electric fields at the cellular level are based on spatially dependent, partial differential equations [21,22]. It is challenging to assume modeling conditions, such as irregular cell shape, nearby cells, and non-linear cell membrane change due to electroporation [23]. This research uses a finite element method (FEM) to deal with those conditions at a computational cost.

In the following, the effects of electroporation and extracellular buffers on the equivalent (bulk) electrical properties are evaluated theoretically. A two-shell model is used to represent the yeast cell (see Figure 1a) under $50 \mu \mathrm{s}(10$ to $60 \mu \mathrm{s})$ and $1 \mu \mathrm{s}(2$ to $3 \mu \mathrm{s})$, 
$400 \mathrm{kV} / \mathrm{m}$ PEF (see Figure 1d). The PEF induce higher transmembrane voltages at cell poles, which provokes electroporation. The electroporation model describes the pore density $N(t)$ and average membrane conductivity due to PEF (see Figure $1 \mathrm{~b}, \mathrm{c}$ ). The 'electroporated' yeast cell is in the center of an infinitesimal cylindrical volume (see Figure 1e). The cylinder is used to evaluate conduction current density $J$ during PEF. The infinitesimal volume describes the yeast suspension (see Figure 1f). The data are calculated and analyzed in terms of the cell's membrane conductivity, the transmembrane voltage, and equivalent relative permittivity $\varepsilon_{e q}$ of the infinitesimal cylinder during the PEF protocol. Membrane conductivity and transmembrane voltage are given as function of $\theta$ angle (see Figure 1e). The low-frequency current increases due to the cell's membrane interface change, altering the sample's electrical characteristic, i.e., $\beta$-dispersion.

(a)

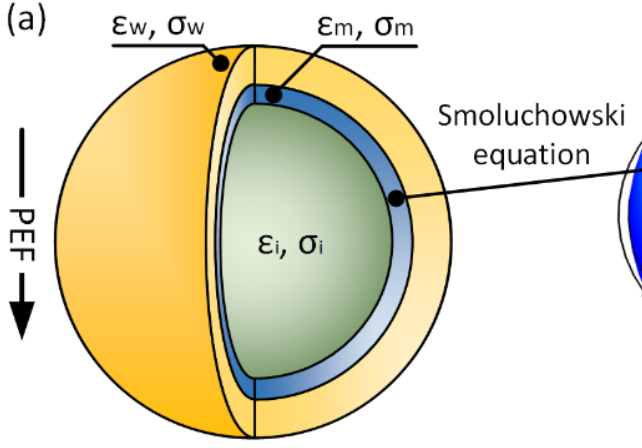

(d)

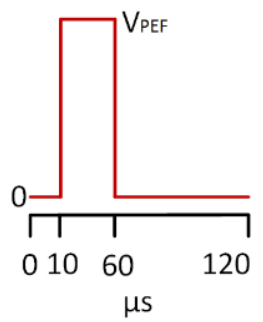

(e) (b)
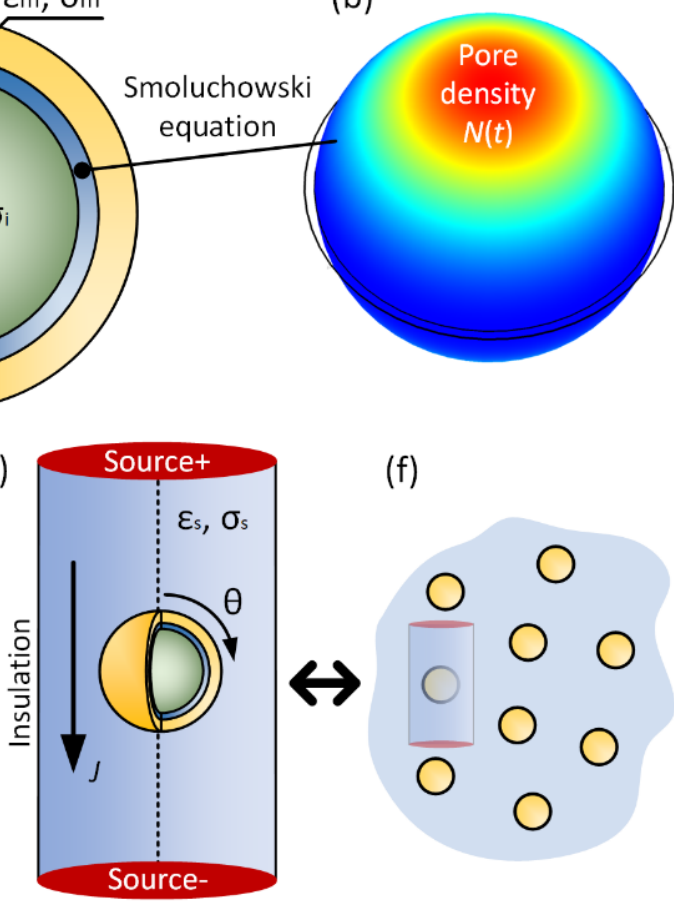

(f)

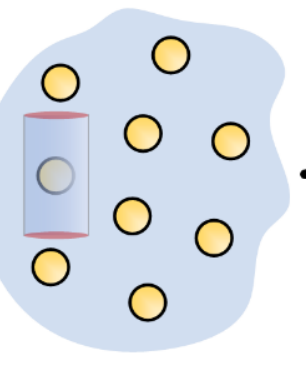

(c)

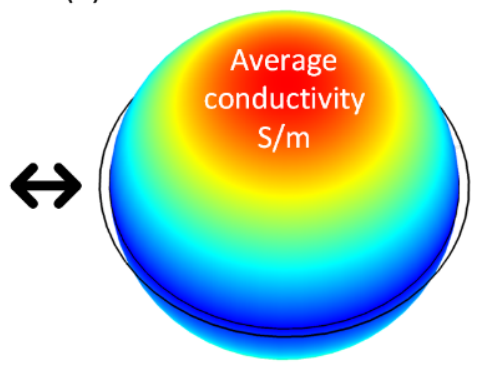

(g)

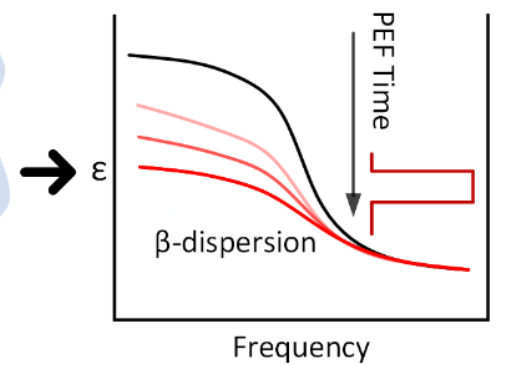

Figure 1. (a) Two-shell whole yeast cell model under PEF. PEF induces higher transmembrane voltages, which increases $(\mathbf{b})$ pore density $N(t)$ and (c) the average membrane conductivity. The color map values are as follows: red means higher and blue means lower. (d) The $50 \mu$ stimulus signal profile, where $\mathrm{V}_{\mathrm{PEF}}$ is calculated to obtain $400 \mathrm{kV} / \mathrm{m}$ maximum PEF. (e) An infinitesimal cylindrical model with one 'electroporated' cell. The $\theta$ angle is used to address membrane conductivity and transmembrane voltage results. (f) The infinitesimal cylinder describes a cell suspension with $1 \%$ yeast concentration ratio. (g) The decrease in the membrane conductivity affects the $\beta$-dispersion of the yeast suspension.

\subsection{Numerical Modeling}

The time-harmonic conduction and displacement currents are solved according to Maxwell-Ampère's law, as given by Equation (1). In this equation, it is assumed that all variations in time occur as steady-state sinusoidal signals. Because of a non-linear condition due to electroporation, the observation is considered to be time-dependent, and linearity is assumed over a small-scale step. Thus, the time step is a stationary problem in the frequency domain using complex values. The fields are represented by amplitude and phase (i.e., phasors), while the frequency is specified as a predefined sweep sinusoidal 
signal input. A frequency range from 100 to $1 \mathrm{MHz}$ is employed, as they are the optimal frequencies for cell membrane sensing [24]:

$$
J=\sigma E+j \omega \varepsilon E
$$

where $J$ is the conduction current density and $E$ is the electric field $(\mathrm{V} / \mathrm{m})$, computed as $E=-\nabla V$ (where $V$ is the electric potential) [25].

The whole cell geometry model is a two-shell yeast model located at a cylindrical spatial media. The model is $2 \mathrm{D}$ axisymmetric, and a revolution in the cylinder axis is used to obtain volumetric results (see the dotted line in Figure 1e). The volumetric model containing one cell is shown in Figure 1e. The whole cell simulation parameters and their description are given in Table 1. Cells of the yeast Saccharomyces cerevisiae are used because detailed electrical properties literature and their ellipsoidal shape are often approximated as a two-shell sphere [26-28]. In this research, a 1\% yeast concentration ratio (i.e., the ratio between cell's volume divided by the total solution) is used, which is approximately $2 \times 10^{8}$ cells $/ \mathrm{mL}$. This is a typical yeast concentration from the experimental point of view [29]. The cell concentration is controlled by adjusting the cylinder volume, i.e., changing the total buffer volume to match the desired concentration.

Table 1. Geometric simulation parameters.

\begin{tabular}{cc}
\hline Symbol & Value \\
\hline Infinitesimal volume cylinder heigh & $30 \mu \mathrm{m}$ \\
\hline Infinitesimal volume cylinder radius & $16.8 \mu \mathrm{m}$ \\
\hline Cell wall thickness & $220 \mathrm{\eta m}^{1}$ \\
\hline Cell membrane thickness & $8 \mathrm{\eta m}^{1}$ \\
\hline Cell radius & $4 \mathrm{~mm}^{1}$ \\
\hline
\end{tabular}

${ }^{1}$ Data from [30].

COMSOL Multiphysics ${ }^{\circledR}$ version 4.4 software is used for FEM modeling and 2D electric currents application ('ec', from the COMSOL's AC/DC Module). The electroporation model is solved in the time domain (as described previously [4,31]), giving results of pore density $N(t)$ and average membrane electrical conductivity (see Appendix A Equations (A1) and (A2)). The simulation steps are defined as linear and were $0.5 \mu$ s when using $50 \mu$ s PEF and $0.01 \mu \mathrm{s}$ when using $1 \mu \mathrm{s}$ PEF. The simulation is run until $120 \mu \mathrm{s}$ (for $50 \mu \mathrm{s}$ PEF) and $20 \mu \mathrm{s}$ (for $1 \mu \mathrm{s}$ PEF) to calculate post-PEF transient effect. The small signal frequency domain is used to calculate equivalent complex permittivity. The boundary conditions were insulation on the curved cylinder surface, and the top and bottom bases were used as sinusoidal and PEF voltage sources. There is a differential bias of $1 \times 10^{-4} \mathrm{~V}$ between the top and bottom boundaries used for small signal analysis. We suppose that our simulation volume behaves as an infinitesimal volume in a whole yeast suspension as the gradient of the voltage in the insulation is less than $2.5 \%$ of the source voltage, and the gradient of the current in the top and bottom sources is less than $2.5 \%$. Those parameters are critical and must be as small as possible. If the gradient in the boundary layers is negligible, then there is no field diffraction in the boundary so that we can assume an infinitesimal volume design model.

A custom mesh is designed for this study. The mesh is edge mapped for bilateral symmetry and mapped as 10 per 1000 quadratic elements for each cell's membrane and wall. Other elements are made using COMSOL's free triangular semiconductor 'fine' pre-set. The maximum element size is set as $3.3 \times 10^{-7} \mathrm{~m}$. The mesh consists of 171,416 tetrahedral elements. The transmembrane voltage due to PEF can be analytically calculated using the Laplace equation [32]. We validated the numerical calculations by comparing them to the analytical solution proposed by Gimsa and Wachner [33]. The maximum relative error between the analytical solution and the computer simulation was $5.18 \%$ (using the 
parameters shown in Table 1). Therefore, we considered our model to be sufficiently accurate for our study.

\subsection{Yeast Cell Passive Properties}

The electrical parameters of the tested materials are listed in Table 2. Low conductivity media (also called 'electroporation buffer') are preferred for mitigating electrolysis during PEF [34], and some buffer composition is reported to improve electroporation efficiency [35]. For the in vitro experiment, the conductivity and osmolality of the buffer can be modulated by changing salts (e.g., $\mathrm{KCl}$ and $\mathrm{NaCl}$ ) and sugars (e.g., sucrose). However, caution must be taken for modeling, as the buffer conductivity influences the cell's wall and membrane conductivity and intracellular conductivity [26-28]. We computed results using three conductivities situations: $1 \times 10^{-3} \mathrm{~S} / \mathrm{m}\left(\right.$ low $\sigma$ ), $50 \times 10^{-3} \mathrm{~S} / \mathrm{m}$ (medium $\sigma$ ) and $0.1 \mathrm{~S} / \mathrm{m}$ (high $\sigma$ ) buffer. It is found that the conductivity of laboratory deionized water is typically $1 \times 10^{-3} \mathrm{~S} / \mathrm{m}$ and final yeast's suspension solutions in a range from $50 \times 10^{-3}$ to $0.2 \mathrm{~S} / \mathrm{m}$ [26]. The membrane channels state is 'closed' (i.e., the lower conductivity end at approximately $0.25 \times 10^{-6} \mathrm{~S} / \mathrm{m}$ ) at 1 to $10 \times 10^{-3} \mathrm{~S} / \mathrm{m}$ buffers and 'increasingly opening' for buffers over $20 \times 10^{-3} \mathrm{~S} / \mathrm{m}$. For a typical $50 \times 10^{-3} \mathrm{~S} / \mathrm{m}$ buffer [35], the membrane conductivity is approximately $0.1 \times 10^{-3} \mathrm{~S} / \mathrm{m}$ [27]. The cell wall is a known negative charged sieve-like structure. Thus, it is the first selective barrier [36]. Some reports say that for a highly conductive medium, the conductivity of the cell's walls is approximately 10 to $20 \%$ of medium conductivity, which may be explained by the wall's porosity and its charges [26]. The cytoplasm is known to be a highly conductive medium, as it holds the necessary salt and protein for a cell's life.

Table 2. Non-linear electroporation model, electrical and geometric parameters of the simulation.

\begin{tabular}{|c|c|c|c|}
\hline Parameter & $\sigma_{\text {Low }}$ Buffer & $\sigma_{\text {Med }}$ Buffer & $\sigma_{\text {High }}$ Buffer \\
\hline External solution conductivity $\left(\sigma_{S}\right)$ & $1 \times 10^{-3}[\mathrm{~S} / \mathrm{m}]$ & $50 \times 10^{-3}[\mathrm{~S} / \mathrm{m}]$ & $0.1[\mathrm{~S} / \mathrm{m}]$ \\
\hline External solution permittivity $\left(\varepsilon_{s}\right)$ & 78 & $78^{1}$ & 77 \\
\hline Cytoplasm's conductivity $\left(\sigma_{i}\right)$ & $0.2[S / \mathrm{m}]$ & $0.55[\mathrm{~S} / \mathrm{m}]$ & $0.6[S / m]$ \\
\hline Cytoplasm's relative permittivity $\left(\varepsilon_{i}\right)$ & 50 & $50^{1}$ & 58 \\
\hline Initial membrane's conductivity $\left(\sigma_{m 0}\right)$ & $0.25 \times 10^{-6}[\mathrm{~S} / \mathrm{m}]$ & $0.1 \times 10^{-3}[\mathrm{~S} / \mathrm{m}]$ & $0.1 \times 10^{-3}[\mathrm{~S} / \mathrm{m}]^{2}$ \\
\hline Membrane's relative permittivity $\left(\varepsilon_{m}\right)$ & 6 & 7.6 & 5.2 \\
\hline Cell wall's conductivity $\left(\sigma_{w}\right)$ & $14 \times 10^{-3}[\mathrm{~S} / \mathrm{m}]$ & $5 \times 10^{-3}[\mathrm{~S} / \mathrm{m}]$ & $20 \times 10^{-3}[\mathrm{~S} / \mathrm{m}]$ \\
\hline Cell wall's relative permittivity $\left(\varepsilon_{w}\right)$ & 60 & $60^{1}$ & 60 \\
\hline
\end{tabular}

\section{Results}

The membrane conductivity, transmembrane voltage, and solution's relative permittivity when using $50 \mu \mathrm{s}$ PEF is shown in Figure 2. During 10 to $60 \mu \mathrm{s}$, the PEF is enabled. All buffers are adequate to induce electroporation transmembrane voltages. The $\sigma_{\text {Low }}$ buffer has the slowest time dynamics (see the post-60 $\mu$ s dynamism of membrane conductivity and transmembrane voltage). This occurs due to the poor buffer-cell interface conductive coupling, which leads to slower capacitive charging and discharging processes. The membrane state change is practically instantaneous when using $\sigma_{\text {Med }}$ and $\sigma_{\text {High }}$ buffers. Additionally, the extent of membrane area affected by electroporation is higher when $\sigma_{\text {High }}$ buffer is used (approximately $-\pi / 2$ to $\pi / 2$ ). 


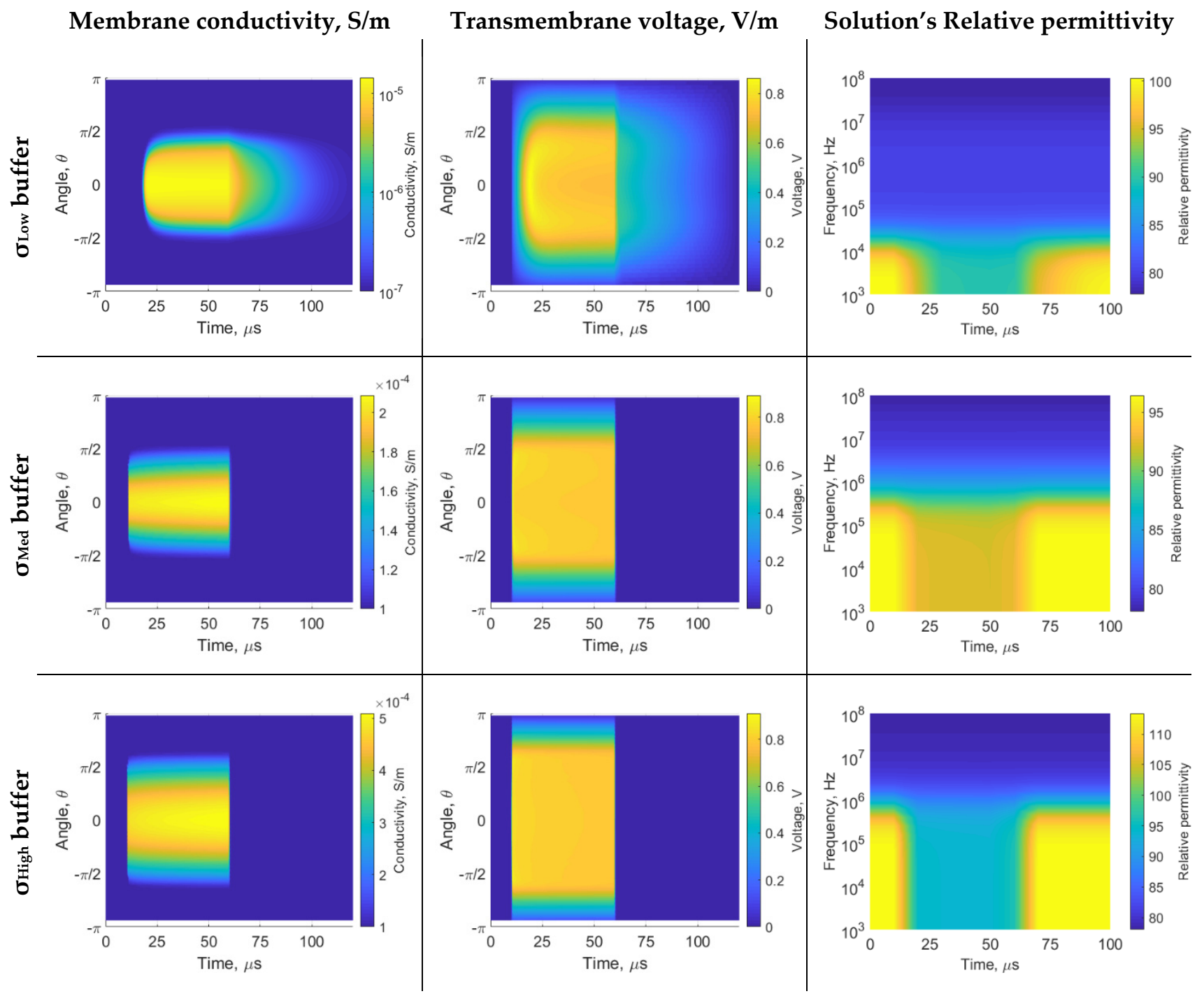

Figure 2. Results of $50 \mu \mathrm{s}$ PEF: Membrane conductivity, transmembrane voltage and solution equivalent relative permittivity. The horizontal axis is the time in $\mu$ s. The PEF starts at $10 \mu$ s and ends at $60 \mu \mathrm{s}$. The vertical axis of the membrane conductivity and transmembrane voltage figures represent the angle location in the membrane. The vertical axis of the solution relative permittivity figures is the sensing frequency ( $1 \mathrm{kHz}$ to $100 \mathrm{MHz}$ range).

Figure 3 shows the cell suspension dielectric properties before and during electroporation, using data from $8 \mu \mathrm{s}$ and $50 \mu$ s time step, respectively (from $50 \mu \mathrm{s}$ PEF). The membrane interface changes due to electroporation and affects the $\beta$-dispersion magnitude. The dispersion center depends on the system's characteristics; the dispersion center is approximately $10 \mathrm{kHz}$ for $\sigma_{\text {Low }}$ buffer and $500 \mathrm{kHz}$ for $\sigma_{\text {Med }}$ and $\sigma_{\text {High }}$ buffer (see the blue arrows at Figure 3 solution's relative permittivity). Frequencies higher than $1 \mathrm{MHz}$ are not suitable for sensing the membrane dispersion, as the displacement current can flow through the cell, which is called 'electrically invisible'. The $\beta$-dispersion is mainly explained by the cell barrier (membrane and wall). The cell wall is described to be electrically distinct from the membrane. Thus, a sub- $\beta$-dispersion is provoked by the cell wall and interfere with the 'main' $\beta$-dispersion. The wall interference starts at $0 \mathrm{~Hz}$ when using $\sigma_{\text {Med }}$ and $\sigma_{\mathrm{High}}$ buffer, as the wall is less conductive than external media. The wall primarily impacts the $\sigma_{\text {Med }}$ buffer $\beta$-dispersion as electrical characteristics of wall and membrane are more similar than $\sigma_{\mathrm{High}}$ buffer. The wall sub- $\beta$-dispersion has its peak indicated by the gold arrows in Figure 3 (gold arrows show the peak trans-wall voltage). 

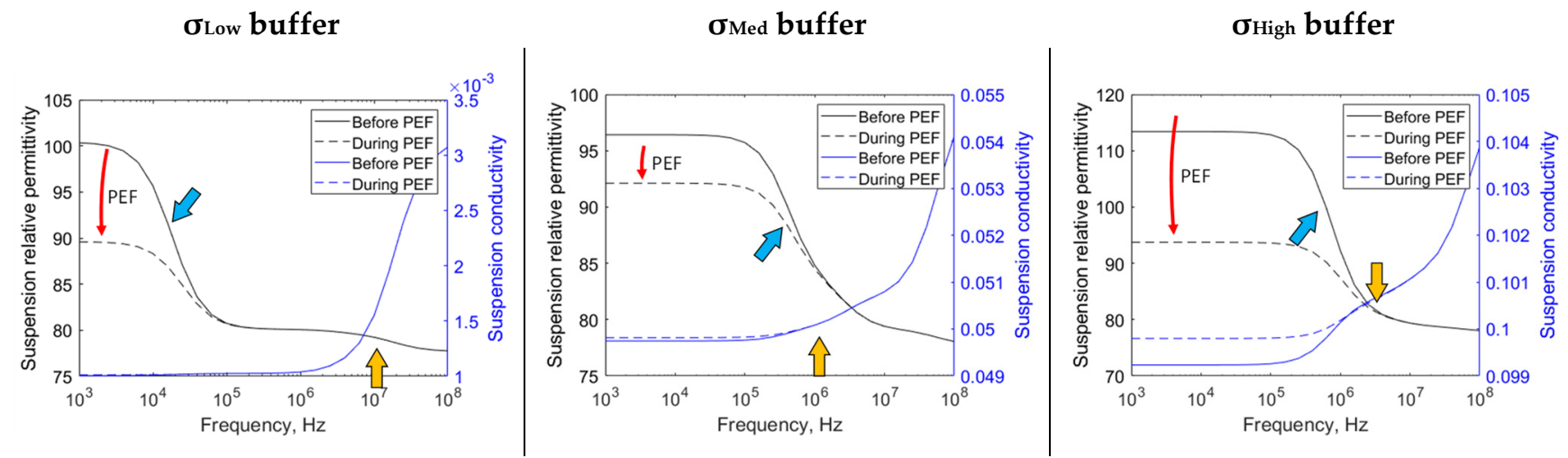

Figure 3. Cell suspension dielectric properties before and during PEF. The electroporation decreases the equivalent solution permittivity. The red arrow indicates the time direction. The blue arrow indicates the membrane main- $\beta$-dispersion. The gold arrow indicates the yeast wall peak sub- $\beta$-dispersion.

The $1 \mu$ s PEF results are shown in Figure 4 . During 2 to $3 \mu$ s, the PEF is enabled. The $\sigma_{\text {Low }}$ buffer slow dynamic cannot charge the membrane sufficiently for electroporation (the membrane charges up to $200 \mathrm{mV}$ ). Thus, the membrane conductivity change is negligible, and the spectrum does not change significantly (i.e., unsuccessful electroporation). The $\sigma_{\text {Med }}$ buffer can charge the membrane sufficiently for electroporation. However, the $1 \mu \mathrm{s}$ does not saturate conductivity, as seen in $50 \mu \mathrm{s}$ PEF (Figure 2). Thus, $\sigma_{\text {Med }}$ buffer $\beta$ dispersion decays only at the end of the 1 us pulse.

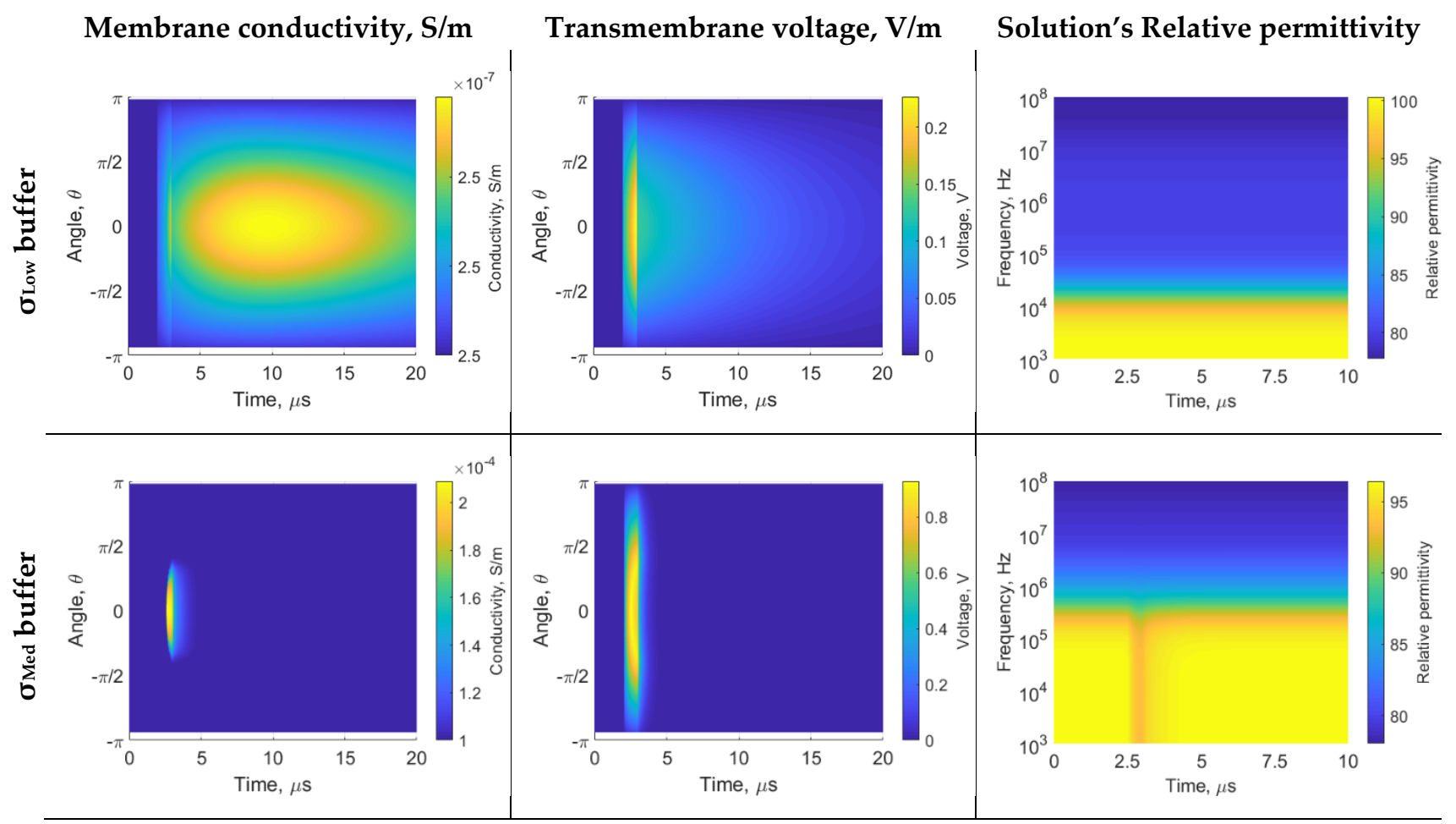

Figure 4. Cont. 

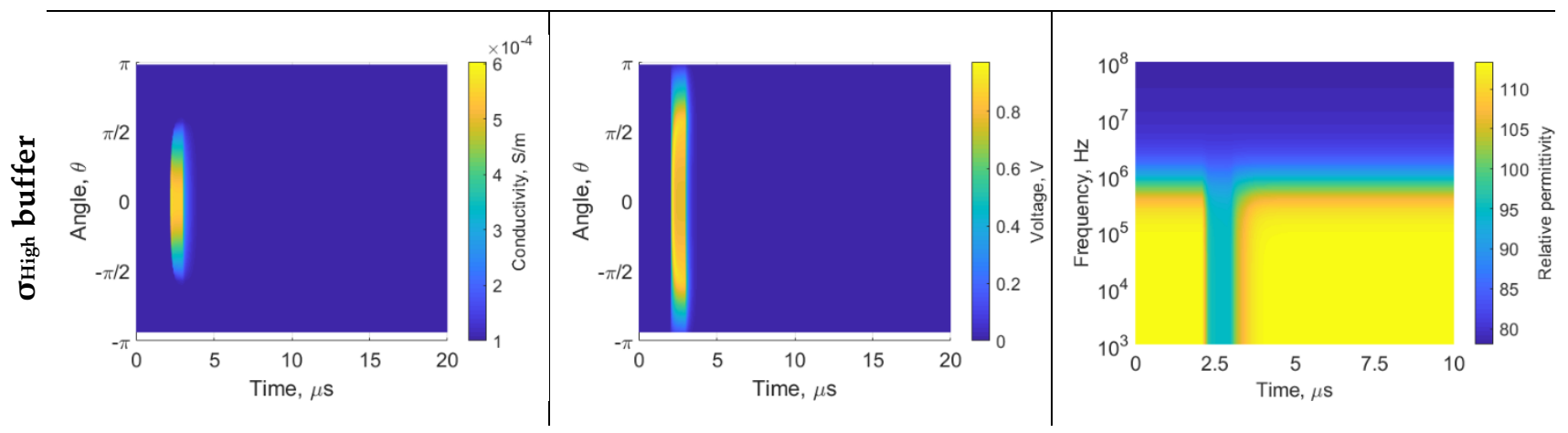

Figure 4. Results of $1 \mu \mathrm{S}$ PEF: membrane conductivity, transmembrane voltage and solution equivalent relative permittivity. The axis description is used within Figure 3. The PEF starts at $2 \mu$ s, and ends at $3 \mu \mathrm{s}$. When using $\sigma_{\text {Low }}$, the membrane conductivity changes are lower than $0.1 \%$.

\section{Discussion}

This study is focused on the impact of cells' relative parameters on the frequency spectrum of impedance, particularly how individual electrical properties affect the dielectric $\beta$-dispersion center. The $\beta$-dispersion is mostly described by the cell membrane interface. The dielectric dispersion dynamics can be used as a design parameter for micro/nano dielectric dispersion modulated sensors. Those sensors may be used for industrial irreversible electroporation or lab on a chip electroporation device [9]. FEM simulation has been used to find the equivalent $\varepsilon$, which depends on the inhomogeneous media. We have shown that an impedance sensor operating up to $1 \mathrm{MHz}$ can perceive the alteration caused by electroporation in cells if the buffer conductivity is higher than $50 \mathrm{mS} / \mathrm{m}$. An infinitesimal volume has been used to simulate a cell suspension, which is a reasonable approach for low density suspension. The electroporation analysis of cells attached or very closed to the microelectrodes [9] can use similar dielectric dispersion dynamics modulated sensors. However, specific cell geometry and properties, cell density, and electrode/chamber design may be simulated to determine appropriate sensor operating frequency and minimum buffer conductivity. The electroporation model is used to assess the membrane conductivity during PEF. The change in membrane conductivity affects the overall, i.e., 'equivalent', properties.

The maximum membrane conductivity for $\sigma_{\text {Low }}, \sigma_{\text {Med }}$, and $\sigma_{\text {High }}$ buffers are $0.01 \mathrm{mS} / \mathrm{m}$, $0.2 \mathrm{mS} / \mathrm{m}$, and $0.5 \mathrm{mS} / \mathrm{m}$, respectively, as shown in Figure 2. Even though we did not replicate the recent electroporated membrane conductivity of $3 \mathrm{mS} / \mathrm{m}$ to $30 \mathrm{mS} / \mathrm{m}$ [37-39], our results are consistent with some early experimental and theoretical works $(0.01 \mathrm{mS} / \mathrm{m}$ to $1 \mathrm{mS} / \mathrm{m}$ ) [32,40-42]. Ramos et al. [43] shows a membrane conductivity of $1 \mu \mathrm{S} / \mathrm{m}$ to $0.01 \mathrm{mS} / \mathrm{m}$ (conversion $\sigma_{m}=h \cdot G_{m}$ [44]) for yeast cells with 0.28 volumetric fraction. These reduction of electroporated membrane conductivity may be caused by volumetric fraction [45]. The present studies are similar to very low cell density, without reduced transmembrane potential caused by cells proximity. Despite the limitations, our findings are consistent with the previous reports of membrane conductivity.

The $\sigma_{\text {Low }}$ buffer, i.e., deionized water, is a 'reasonable' insulator from a biological media perspective. We have observed that some cell types may not be compatible with this medium's osmolarity. The electrical characteristics of this buffer are similar to the cell wall. Therefore, the effects of the buffer-wall interface are reduced, i.e., diffraction of the electric field and wall voltage drop. Because most of the dispersion is created only by the cell membrane, it tends to have the dispersion center at low frequency due to the thin membrane (the dispersion center, in this case, is near $10 \mathrm{kHz}$ ). The $\sigma_{\text {High }}$ medium is more typical for liquid foods $[4,38,46]$. The $\sigma_{\text {Med }}$ and $\sigma_{\text {High }}$ buffers are more similar regarding dispersion center location. Those have the dispersion center near $500 \mathrm{kHz}$. From the membrane sensing point of view, it is interesting to see that the cell's interface dispersion is higher than $10 \mathrm{kHz}$, as frequencies sub-10 $\mathrm{kHz}$ are probably contaminated with the chambers' 
electrolytic double layer effect, i.e., electrode polarization and $\alpha$-dispersion [26]. Therefore, this sensing approach can mitigate the unwanted impact by using measurements higher than $100 \mathrm{kHz}$. However, we cannot exceed $1 \mathrm{MHz}$, as the membrane and wall become 'electrically invisible'. In other words, the voltage drop due to the cell's interface is primarily linear. We did not notice changes in the spectrum at the time of electroporation (see the relative permittivity in Figure 2). Other researchers reported similar values [23,39,47].

The electroporation is modeled as the change in membrane conductivity due to the transmembrane voltage. When the transmembrane voltage reaches a certain value $(\sim 0.2-1 \mathrm{~V})$ [48], membrane permeability increases as a consequence of the formation of hydrophilic pores in the lipid bilayer, leading to an increase in membrane conductivity (see Appendix A Equation (A2)). The $\sigma_{\text {Low }}$ buffer has slower membrane (dis)charging dynamics (see the transmembrane voltage dynamics in Figure 2). Therefore, there is a direct effect on the conductivity of the membrane and the overall relative permittivity. For applications of molecule transfer, using a low conductivity buffer may be interesting to provide a slower dynamic transfer window, which is easier to operate from a control system perspective. Some authors have shown that a low conductivity buffer affects electroporation or enhances cell uptake [49-51]. Furthermore, the low conductivity buffer is attractive, as it results in lower electrical currents, and consequently, mitigates thermal or electrochemical effects. For purely irreversible electroporation PEF or arc plasm applications, this is the most suitable buffer to destroy the cell's membrane. We observe that caution is needed if using fast PEF protocols. The $1 \mu \mathrm{s}$ was not adequate to provoke electroporation when using $\sigma_{\text {Low }}$ buffer. Additionally, the $1 \mu \mathrm{s}$ PEF combined with $\sigma_{\text {Med }}$ buffer is not fast enough to saturate the transmembrane voltage; thus, it may be the approximate lower threshold conductivity buffer to be used with $1 \mu \mathrm{s}$ PEF. The dielectric dispersion sensing mechanism is capable of detecting the electroporation state: there are no alterations at $\sigma_{\text {Low }}$ buffer (unsuccessful electroporation), late alterations at $\sigma_{\text {Med }}$ buffer (caution state), and alterations at $\sigma_{\text {High }}$ buffer (successful electroporation, see Figure 4).

The two-shell models are widely used in scientific research. However, they rely on various assumptions, e.g., spheric cells, nothing embedded in the wall or membrane, and homogeneous intracellular media [30]. Those may be a limiting factor in the analysis above $10 \mathrm{MHz}[26,28]$. However, this work, as well as others in the literature, have demonstrated that to sense the cell's primally barrier (i.e., cell membrane), we should not exceed approximately $1 \mathrm{MHz}[23,24,39]$. The sub- $\beta$-dispersion (see Figure 2 gold arrow) is caused by the cell wall. The yeast experimental and simulations results described by Asami attributes sub-dispersions due to cell wall and vacuole [26]. It is known that the entire spectrum is interdependent (as dispersive effects overlap) [52], and PEF is reported to induce permeabilization in the entire cell barrier [53]. Therefore, we believe that at present, it is appropriate to evaluate the electroporation as a sum of effects (mixed results of membrane and wall). Even if the information generates a discrete event, it would be suitable in some scenarios, such as cold pasteurization by PEF. The membrane electroporation state change is almost instantaneous with a medium or high conductivity buffer. Thus, if a single pulse is used in these cases, the reversible electroporation may be modeled as a discrete event.

\section{Conclusions}

Yeasts may contaminate liquid food, causing financial or health problems. The PEF systems can eliminate microorganisms. However, those systems lack a directly electroporation feedback. This type of sensing is complex, as other phenomena result from direct current in an ionic media, i.e., electrode polarization. Disturbances in the spectrum due to electrode polarization are usually up to $10 \mathrm{kHz}$. We have demonstrated that it is feasible to supervise electroporation using impedance. The biological media are characterized by the $\beta$-dispersion, which is provoked mainly by the cell membrane. If the cell membrane changes due to electroporation, the biological media dispersion changes. A numerical study of a yeast suspension process can calculate the dielectric dispersion due to the cell 
barrier, external medial (buffer), and electroporation. Yeast cell suspension $\beta$-dispersion reduces due to the increase in the membrane conductivity. This approach may be used to develop a microsensor for use on an industrial electroporation line or an electroporation lab on a chip device.

Author Contributions: Conceptualization, methodology, and formal analysis, G.B.P. and D.O.H.S.; software, validation, and visualization, G.B.P. and J.R.d.S.; investigation, G.B.P.; resources and funding acquisition, D.O.H.S.; writing, all authors contributed; supervision, W.Y. and D.O.H.S. All authors have read and agreed to the published version of the manuscript.

Funding: This work was supported in part by the research funding agencies Coordenação de Aperfeiçoamento de Pessoal de Nível Superior (CAPES) and in part by the Conselho Nacional de Desenvolvimento Científico e Tecnológico (CNPq).

Institutional Review Board Statement: Not applicable. This study does not involve humans.

Informed Consent Statement: Not applicable. This study does not involve humans.

Conflicts of Interest: The authors declare no conflict of interest.

\section{Appendix A}

A non-linear model of electroporation can be used to simplify the Smoluchowski equation to describe the pore density $N(t)$, as [54]:

$$
\frac{d N(t)}{d t}=\alpha e^{\left(\frac{V_{m}(t)}{V_{e p}}\right)^{2}}\left(1-\frac{N(t)}{N_{0}} e^{-q\left(\frac{V_{m}(t)}{V_{e p}}\right)^{2}}\right)
$$

where $V_{m}(t)$ is the transmembrane voltage, $V_{e p}$ is the electroporation voltage, $N_{0}$ is the pore density at $V_{m}=0 \mathrm{~V}$, and $\alpha$ and $\mathrm{q}$ are constants. Equation (A1) was implemented in COMSOL using the Weak Form Boundary PDE physics application mode on all membrane surfaces.

The regions where pores are formed present average conductivity of $[42,45,55]$ :

$$
\sigma_{m}(t)=\sigma_{m_{0}}+N(t) \sigma_{p} \pi r_{p}^{2} K
$$

where $\sigma_{m 0}$ is the membrane conductivity without electroporation, $\sigma_{p}$ is the conductivity of pore, $r_{p}$ is the pore radius, and $K$ is:

$$
K=\frac{e^{v_{m}}-1}{\frac{w_{0} e^{z v_{0}-\eta v_{m}}}{w_{0}-\eta v_{m}} e^{v_{m}}-\frac{w_{0} e^{w_{0}+\eta v_{m}}+\eta v_{m}}{w_{0}+\eta v_{m}}}
$$

where $w_{0}$ is the energy barrier inside the pore, $\eta$ is the relative entrance length of the pore, and $v_{m}=\frac{q_{e}}{k T} V_{m}$ is the non-dimensional transmembrane voltage.

The pore conductivity is [56]:

$$
\sigma_{p}=\frac{\sigma_{w}-\sigma_{i}}{\ln \left(\frac{\sigma_{w}}{\sigma_{i}}\right)}
$$

The cell and electroporation model parameters are given in Table A1. 
Table A1. Non-linear electroporation model, electrical and geometric parameters of simulation.

\begin{tabular}{|c|c|c|c|}
\hline Parameter & Symbol & Value & References \\
\hline External conductivity & $\sigma_{e}$ & See Table 2 & - \\
\hline External permittivity & $\varepsilon_{e}$ & See Table 2 & - \\
\hline Membrane permittivity & $\varepsilon_{m}$ & See Table 2 & - \\
\hline Wall membrane conductivity & $\sigma_{w}$ & See Table 2 & - \\
\hline Wall membrane permittivity & $\varepsilon_{w}$ & See Table 2 & - \\
\hline Cytoplasm conductivity & $\sigma_{i}$ & See Table 2 & - \\
\hline Cytoplasm permittivity & $\varepsilon_{i}$ & See Table 2 & - \\
\hline Cell radius & $R$ & $5 \mu \mathrm{m}$ & [30] \\
\hline Thickness membrane & $h_{m}$ & $8 \mathrm{~nm}$ & {$[30,57]$} \\
\hline Thickness wall & $h_{w}$ & $220 \mathrm{~nm}$ & {$[27,30]$} \\
\hline Electroporation constant & $q$ & 2.46 & {$[54,55]$} \\
\hline Electroporation constant & $\alpha$ & $109 \mathrm{~m}^{2} \mathrm{~s}^{-1}$ & {$[42,54,55]$} \\
\hline Pore density at $\mathrm{V}_{\mathrm{m}}=0 \mathrm{~V}$ & $N_{0}$ & $1.5 \times 10^{9} \mathrm{~m}^{-2}$ & {$[42,54,55]$} \\
\hline Electroporation voltage & $V_{e p}$ & $258 \mathrm{mV}$ & {$[42,54,55]$} \\
\hline Pore energy barrier & $W_{0}$ & 2.65 & {$[42,54,55]$} \\
\hline Relative length of the pore & $\eta$ & $0.15 \mathrm{~nm}$ & {$[42,54,55]$} \\
\hline Pore radius & $r_{p}$ & $0.8 \mathrm{~nm}$ & {$[42,54,55]$} \\
\hline Boltzmann constant & $k$ & $1.38 \times 10^{-23} \mathrm{~m}^{2} \mathrm{kgs}^{-2} \mathrm{~K}^{-1}$ & {$[42,54,55]$} \\
\hline Temperature & $T$ & $295 \mathrm{~K}$ & {$[42,54,55]$} \\
\hline
\end{tabular}

\section{References}

1. Ozyigit, I.I. Gene transfer to plants by electroporation: Methods and applications. Mol. Biol. Rep. 2020, 47, 3195-3210. [CrossRef]

2. Rangel, M.M.M.; Luz, J.C.S.; Oliveira, K.D.; Ojeda, J.; Freytag, J.O.; Suzuki, D.O. Electrochemotherapy in the treatment of neoplasms in dogs and cats. Austral J. Vet. Sci. 2019, 51, 45-51. [CrossRef]

3. Geboers, B.; Scheffer, H.J.; Graybill, P.M.; Ruarus, A.H.; Nieuwenhuizen, S.; Puijk, R.S.; van den Tol, P.M.; Davalos, R.V.; Rubinsky, B.; de Gruijl, T.D.; et al. High-Voltage Electrical Pulses in Oncology: Irreversible Electroporation, Electrochemotherapy, Gene Electrotransfer, Electrofusion, and Electroimmunotherapy. Radiology 2020, 295, 254-272. [CrossRef] [PubMed]

4. Pintarelli, G.B.; Ramos, C.T.S.; Da Silva, J.R.; Rossi, M.J.; Suzuki, D.O.H. Sensing of Yeast Inactivation by Electroporation. IEEE Sens. J. 2021, 21, 12027-12035. [CrossRef]

5. Reineke, K.; Schottroff, F.; Meneses, N.; Knorr, D. Sterilization of liquid foods by pulsed electric fields-an innovative ultra-high temperature process. Front. Microbiol. 2015, 6, 400. [CrossRef]

6. Ghorbel, A.; Mir, L.M.; García-Sánchez, T. Conductive nanoparticles improve cell electropermeabilization. Nanotechnology 2019, 30, 495101. [CrossRef]

7. Pintarelli, G.B.; Berkenbrock, J.A.; Rassele, A.; Rangel, M.M.M.; Suzuki, D.O.H. Computer simulation of commercial conductive gels and their application to increase the safety of electrochemotherapy treatment. Med. Eng. Phys. 2019, 74, 99-105. [CrossRef]

8. Lopes, L.B.; Pintarelli, G.B.; dos Santos, C.S.F.; Suzuki, D.O.H. Computer optimization of conductive gels for electrochemotherapy. Med. Eng. Phys. 2021, 98, 133-139. [CrossRef]

9. Zhang, Y.; Yan, Z.; Xia, X.; Lin, Y. A novel electroporation system for living cell staining and membrane dynamics interrogation. Micromachines 2020, 11, 767. [CrossRef]

10. Bazzolo, B.; Sieni, E.; Zamuner, A.; Roso, M.; Russo, T.; Gloria, A.; Dettin, M.; Conconi, M.T. Breast cancer cell cultures on electrospun poly( $\varepsilon$-caprolactone) as a potential tool for preclinical studies on anticancer treatments. Bioengineering $2021,8,1$. [CrossRef]

11. Kotnik, T.; Kramar, P.; Pucihar, G.; Miklavcic, D.; Tarek, M. Cell membrane electroporation- Part 1: The phenomenon. IEEE Electr. Insul. Mag. 2012, 28, 14-23. [CrossRef]

12. Haberl, S.; Miklavcic, D.; Sersa, G.; Frey, W.; Rubinsky, B. Cell membrane electroporation-Part 2: The applications. IEEE Electr. Insul. Mag. 2013, 29, 29-37. [CrossRef]

13. Weaver, J.C.; Smith, K.C.; Esser, A.T.; Son, R.S.; Gowrishankar, T.R. A brief overview of electroporation pulse strength-duration space: A region where additional intracellular effects are expected. Bioelectrochemistry 2012, 87, 236-243. [CrossRef] [PubMed] 
14. Rubinsky, L.; Guenther, E.; Mikus, P.; Stehling, M.; Rubinsky, B. Electrolytic Effects During Tissue Ablation by Electroporation. Technol. Cancer Res. Treat. 2016, 15, NP95-NP103. [CrossRef]

15. Zhuang, J.; Kolb, J.F. Time domain dielectric spectroscopy of nanosecond pulsed electric field induced changes in dielectric properties of pig whole blood. Bioelectrochemistry 2015, 103, 28-33. [CrossRef]

16. Mescia, L.; Chiapperino, M.A.; Bia, P.; Gielis, J.; Caratelli, D. Modeling of Electroporation Induced by Pulsed Electric Fields in Irregularly Shaped Cells. IEEE Trans. Biomed. Eng. 2018, 65, 414-423. [CrossRef]

17. Kotnik, T.; Rems, L.; Tarek, M.; Miklavčič, D. Membrane Electroporation and Electropermeabilization: Mechanisms and Models Annu. Rev. Biophys. 2019, 48, 63-91. [CrossRef]

18. Zhao, Y.; Bhonsle, S.; Dong, S.; Lv, Y.; Liu, H.; Safaai-Jazi, A.; Davalos, R.V.; Yao, C. Characterization of Conductivity Changes During High-Frequency Irreversible Electroporation for Treatment Planning. IEEE Trans. Biomed. Eng. 2018, 65, 1810-1819. [CrossRef]

19. Pavlin, M.; Kandušer, M.; Reberšek, M.; Pucihar, G.; Hart, F.X.; Magjarevićcacute, R.; Miklavčič, D. Effect of Cell Electroporation on the Conductivity of a Cell Suspension. Biophys. J. 2005, 88, 4378-4390. [CrossRef]

20. Schwan, H.P. Electrical Properties of Tissue and Cell Suspensions. In Advances in Biological and Medical Physics; Elsevier: Amsterdam, The Netherlands, 1957; pp. 147-209.

21. Pauly, H.; Schwan, H.P. Über die Impedanz einer Suspension von kugelförmigen Teilchen mit einer Schale. Zeitschrift für Naturforsch. B 1959, 14, 125-131. [CrossRef]

22. Weaver, J.; Astumian, R. The response of living cells to very weak electric fields: The thermal noise limit. Science 1990, 247, 459-462. [CrossRef] [PubMed]

23. Gowrishankar, T.R.; Weaver, J.C. An approach to electrical modeling of single and multiple cells. Proc. Natl. Acad. Sci. USA 2003, 100, 3203-3208. [CrossRef] [PubMed]

24. Xu, Y.; Xie, X.; Duan, Y.; Wang, L.; Cheng, Z.; Cheng, J. A review of impedance measurements of whole cells. Biosens. Bioelectron. 2016, 77, 824-836. [CrossRef] [PubMed]

25. Bastos, J.P.A.; Sadowski, N. Magnetic Materials and 3D Finite Element Modeling; CRC Press: Boca Raton, FL, USA, 2017; Volume 40, ISBN 9781315215624.

26. Asami, K.; Yonezawa, T. Dielectric behavior of wild-type yeast and vacuole-deficient mutant over a frequency range of $10 \mathrm{kHz}$ to 10 GHz. Biophys. J. 1996, 71, 2192-2200. [CrossRef]

27. Hölzel, R.; Lamprecht, I. Dielectric properties of yeast cells as determined by electrorotation. Biochim. Biophys. Acta-Biomembr. 1992, 1104, 195-200. [CrossRef]

28. Raicu, V.; Raicu, G.; Turcu, G. Dielectric properties of yeast cells as simulated by the two-shell model. Biochim. Biophys. Acta-Bioenerg. 1996, 1274, 143-148. [CrossRef]

29. El Zakhem, H.; Lanoisellé, J.-L.; Lebovka, N.I.; Nonus, M.; Vorobiev, E. The early stages of Saccharomyces cerevisiae yeast suspensions damage in moderate pulsed electric fields. Colloids Surf. B Biointerfaces 2006, 47, 189-197. [CrossRef]

30. Lyu, C.; Wang, J.; Powell-Palm, M.; Rubinsky, B. Simultaneous electroporation and dielectrophoresis in non-electrolytic micro/nano-electroporation. Sci. Rep. 2018, 8, 2481. [CrossRef]

31. Costa, J.A.; de Oliveira, P.X.; Pereira, L.S.; Rodrigues, J.; Suzuki, D.O.H. Sensitivity Analysis of a Nuclear Electroporation Model-A Theoretical Study. IEEE Trans. Dielectr. Electr. Insul. 2021, 28, 1850-1858. [CrossRef]

32. Suzuki, D.O.H.; Ramos, A.; Ribeiro, M.C.M.; Cazarolli, L.H.; Silva, F.R.M.B.; Leite, L.D.; Marques, J.L.B. Theoretical and Experimental Analysis of Electroporated Membrane Conductance in Cell Suspension. IEEE Trans. Biomed. Eng. 2011, 58, 3310-3318. [CrossRef]

33. Gimsa, J.; Wachner, D. Analytical Description of the Transmembrane Voltage Induced on Arbitrarily Oriented Ellipsoidal and Cylindrical Cells. Biophys. J. 2001, 81, 1888-1896. [CrossRef]

34. Saulis, G.; Lapè, R.; Pranevičiūte, R.; Mickevičius, D. Changes of the solution pH due to exposure by high-voltage electric pulses. Bioelectrochemistry 2005, 67, 101-108. [CrossRef] [PubMed]

35. Sherba, J.J.; Hogquist, S.; Lin, H.; Shan, J.W.; Shreiber, D.I.; Zahn, J.D. The effects of electroporation buffer composition on cell viability and electro-transfection efficiency. Sci. Rep. 2020, 10, 3053. [CrossRef] [PubMed]

36. Aouida, M.; Tounekti, O.; Belhadj, O.; Mir, L.M. Comparative roles of the cell wall and cell membrane in limiting uptake of xenobiotic molecules by Saccharomyces cerevisiae. Antimicrob. Agents Chemother. 2003, 47, 2012-2014. [CrossRef]

37. Guo, F.; Qian, K.; Zhang, L.; Deng, H.; Li, X.; Zhou, J.; Wang, J. Anisotropic conductivity for single-cell electroporation simulation with tangentially dispersive membrane. Electrochim. Acta 2021, 385, 138426. [CrossRef]

38. Yan, Z.; Hao, C.; Yin, L.; Liu, K.; Qiu, J. Simulation of the influence of temperature on the dynamic process of electroporation based on finite element analysis. IEEE Trans. Plasma Sci. 2021, 49, 2839-2850. [CrossRef]

39. Chiapperino, M.A.; Bia, P.; Lamacchia, C.M.; Mescia, L. Electroporation modelling of irregular nucleated cells including pore radius dynamics. Electronics 2019, 8, 1477. [CrossRef]

40. Schmeer, M.; Seipp, T.; Pliquett, U.; Kakorin, S.; Neumann, E. Mechanism for the conductivity changes caused by membrane electroporation of CHO cell-pellets. Phys. Chem. Chem. Phys. 2004, 6, 5564-5574. [CrossRef]

41. Kakorin, S.; Neumann, E. Ionic conductivity of electroporated lipid bilayer membranes. Bioelectrochemistry 2002, 56, 163-166. [CrossRef] 
42. Pucihar, G.; Miklavčič, D.; Kotnik, T. A time-dependent numerical model of transmembrane voltage inducement and electroporation of irregularly shaped cells. IEEE Trans. Biomed. Eng. 2009, 56, 1491-1501. [CrossRef]

43. Ramos, A.; Schneider, A.L.S.; Suzuki, D.O.H.; Marques, J.L.B. Sinusoidal signal analysis of electroporation in biological cells. IEEE Trans. Biomed. Eng. 2012, 59, 2965-2973. [CrossRef] [PubMed]

44. Arnold, W.M.; Schmutzler, R.K.; Schmutzler, A.G.; van der Ven, H.; Al-Hasani, S.; Krebs, D.; Zimmermann, U. Electro-rotation of mouse oocytes: Single-cell measurements of zona-intact and zona-free cells and of the isolated zona pellucida. Biochim. Biophys. Acta (BBA)-Biomembr. 1987, 905, 454-464. [CrossRef]

45. Ramos, A.; Suzuki, D.O.H.; Marques, J.L.B. Numerical study of the electrical conductivity and polarization in a suspension of spherical cells. Bioelectrochemistry 2006, 68, 213-217. [CrossRef]

46. Al-Hilphy, A.R.S. Electrical Field (AC) for Non Thermal Milk Pasteurization. J. Nutr. Food Sci. 2012, 2, 177-181. [CrossRef]

47. Li, S.; Chen, X.; Han, F. Simulation of Cell Dielectric Properties Based on COMSOL. Proc. Int. Conf. Artif. Life Robot. 2018, 23, 603-606. [CrossRef]

48. Teissié, J.; Rols, M.P. An experimental evaluation of the critical potential difference inducing cell membrane electropermeabilization. Biophys. J. 1993, 65, 409-413. [CrossRef]

49. Silve, A.; Leray, I.; Poignard, C.; Mir, L.M. Impact of external medium conductivity on cell membrane electropermeabilization by microsecond and nanosecond electric pulses. Sci. Rep. 2016, 6, 19957. [CrossRef] [PubMed]

50. Muraji, M.; Taniguchi, H.; Tatebe, W.; Berg, H. Examination of the relationship between parameters to determine electropermeability of Saccharomyces cerevisiae. Bioelectrochem. Bioenerg. 1999, 48, 485-488. [CrossRef]

51. Djuzenova, C.S.; Zimmermann, U.; Frank, H.; Sukhorukov, V.L.; Richter, E.; Fuhr, G. Effect of medium conductivity and composition on the uptake of propidium iodide into electropermeabilized myeloma cells. Biochim. Biophys. Acta-Biomembr. 1996, 1284, 143-152. [CrossRef]

52. Di Biasio, A.; Ambrosone, L.; Cametti, C. The Dielectric Behavior of Nonspherical Biological Cell Suspensions: An Analytic Approach. Biophys. J. 2010, 99, 163-174. [CrossRef]

53. Stirke, A.; Celiesiute-Germaniene, R.; Zimkus, A.; Zurauskiene, N.; Simonis, P.; Dervinis, A.; Ramanavicius, A.; Balevicius, S. The link between yeast cell wall porosity and plasma membrane permeability after PEF treatment. Sci. Rep. 2019, 9, 14731. [CrossRef]

54. Neu, J.C.; Krassowska, W. Asymptotic model of electroporation. Phys. Rev. E 1999, 59, 3471-3482. [CrossRef]

55. Smith, K.C.; Weaver, J.C. Active Mechanisms Are Needed to Describe Cell Responses to Submicrosecond, Megavolt-per-Meter Pulses: Cell Models for Ultrashort Pulses. Biophys. J. 2008, 95, 1547-1563. [CrossRef] [PubMed]

56. Rems, L.; Ušaj, M.; Kandušer, M.; Reberšek, M.; Miklavčič, D.; Pucihar, G. Cell electrofusion using nanosecond electric pulses. Sci. Rep. 2013, 3, 3382. [CrossRef] [PubMed]

57. Huang, Y.; Holzel, R.; Pethig, R.; Wang, X.-B. Differences in the AC electrodynamics of viable and non-viable yeast cells determined through combined dielectrophoresis and electrorotation studies. Phys. Med. Biol. 1992, 37, 1499-1517. [CrossRef] 